\title{
Ocorrência de Bipolaris maydis Causando Mancha Foliar em Paspalum atratum cv. Pojuca no Brasil
}

\author{
José R. N. Anjos', Maria J. A. Charchar ${ }^{1}$, Rogério N. Teixeira² \& Sérgio S. N. Anjos ${ }^{3}$ \\ ${ }^{1}$ Centro de Pesquisa Agropecuária dos Cerrados, Empresa Brasileira de Pesquisa Agropecuária, Cx. Postal 08223, \\ CEP 73301-970, Planaltina, DF, e-mail: ribamar@cpac.embrapa.br; ${ }^{2}$ Embrapa Transferência de Tecnologia, \\ Cx. Postal 06840, CEP 71701-970, Brasília, DF; ${ }^{3}$ Faculdade de Ciências da Saúde, Ciências Farmacêuticas, \\ Universidade de Brasília, CEP 70910-900, Brasília, DF
}

(Aceito para publicação em 14/04/2004)

Autor para correspondência: José Ribamar N. Anjos

ANJOS, J.R.N., CHARCHAR, M.J.A., TEIXEIRA, R.N. \& ANJOS, S.S.N. Ocorrência de Bipolaris maydis causando mancha foliar em Paspalum atratum cv. Pojuca no Brasil. Fitopatologia Brasileira 29:656-658. 2004.

\section{RESUMO}

Bipolaris maydis foi consistentemente isolado de plantas de Paspalum atratum cv. Pojuca com sintomas de manchas foliares em $100 \%$ das plantas de uma população no Cerrado, em 2002. Testes de patogenicidade em casa de vegetação e o subseqüente reisolamento do fungo confirmaram a hipótese de que $B$. maydis é o agente etiológico da mancha foliar de P. atratum cv. Pojuca. Os primeiros sintomas apareceram em todas as mudas inoculadas, quatro a cinco dias após a inoculação. Sete outras espécies de gramíneas foram suscetíveis ao fungo. A ocorrência de manchas foliares de Pojuca causadas por B. maydis é relatada pela primeira vez no Brasil.

Palavras-chave adicionais: Helminthosporium maydis, patogenicidade, gramínea, forrageira, semente.

\section{ABSTRACT}

Occurrence of Bipolaris maydis causing leaf spot in Paspalum atratum cv. ojuca in Brazil

Bipolaris maydis was consistently isolated from infected Paspalum atratum cv. Pojuca plants showing leaf spot symptoms in the Cerrado of Brazil, in 2002. Pathogenicity tests under greenhouse conditions and subsequent reisolations of $B$. maydis from artificially inoculated Pojuca seedlings confirmed the hypothesis that this fungus was the causal agent of the disease. Symptoms of leaf spot appeared four days after inoculation in $100 \%$ of the inoculated Pojuca plants. All seven species of grasses evaluated were susceptible to $B$. maydis. The occurrence of leaf spot of Pojuca caused by B. maydis is reported for the first time in Brazil.
O capim Paspalum atratum Swallen cv. Pojuca é uma gramínea forrageira perene, adaptada a solos ácidos e de baixa fertilidade, indicada para áreas úmidas de baixadas sujeitas a alagamento temporário, ou mesmo para localidades com altas precipitações pluviométricas (Leite \& Fernandes, 1999). No entanto, ele tem bom desempenho também na pré-Amazônia e nas regiões Central, Norte e Sul do Cerrado (Embrapa Cerrados, 2000). Suas características de alta produção de forragem, boa aceitação por bovinos e eqüinos e boa resistência ao ataque da cigarrinha-das-pastagens (Deois flavopicta Stal) (Embrapa Cerrados, 2000; Leite et al., 2001), entre outras, fazem com que o capim Pojuca seja uma boa alternativa a outras gramíneas forrageiras. Até o momento, não há relatos ou referências sobre a ocorrência de fitopatógenos causando manchas foliares nessa forrageira em condições naturais no Brasil.

Em abril de 2002, foram observadas manchas foliares severas em $100 \%$ das plantas de uma população de Pojuca com aproximadamente um ano de idade, em um experimento de produção de sementes de forrageiras, no Campo Experi- mental da Embrapa, Transferência de Tecnologia, Fazenda Sucupira, Gama, DF. Os sintomas consistiam de grande quantidade de lesões variando de elípticas a alongadas, de coloração marrom (Figura 1-A), cobrindo acima de 50\% da área foliar das plantas.

O objetivo desse trabalho foi identificar o agente etiológico das manchas foliares de Pojuca constatado em condições naturais no Distrito Federal, avaliar sua patogenicidade em mudas de Pojuca e de outras gramíneas.

$\mathrm{O}$ isolamento do agente etiológico foi efetuado a partir de folhas lesionadas, em BDA + estreptomicina. Culturas monospóricas de Bipolaris sp. provenientes deste isolamento foram remetidas para o CABI Bioscience, em Egham, Surrey, Reino Unido para identificação da espécie.

Para confirmar a patogenicidade desse isolado, mudas de P. atratum cv. Pojuca foram inoculadas usando micélio e esporos de uma cultura monospórica, multiplicada em BDA durante seis dias, obtidos por maceração em em água destilada estéril, sendo a suspensão de esporos ajustada à concentração de $2 \times 10^{4}$ conídios $/ \mathrm{ml}$, utilizando-se uma câmara de 
Ocorrência de Bipolaris maydis causando mancha foliar em ...

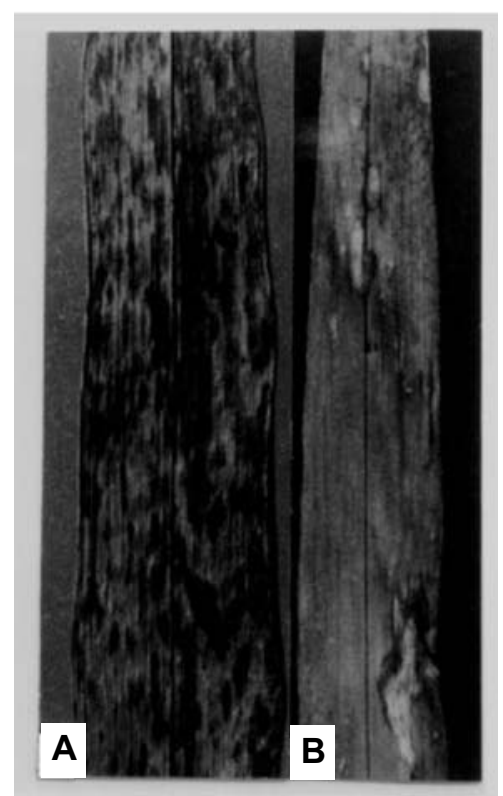

FIG. 1 - Sintomas de manchas foliares em Paspalum atratum cv. Pojuca induzidas por Bipolaris maydis. A) Sintomas em condições de campo. B) Sintomas após inoculação artificial com B. maydis pelo método de pulverização com suspensão de conídios.

Neubauer. A suspensão do inóculo foi pulverizada com atomizador manual em folhas de 20 mudas sadias de 20 dias de idade, mantidas em casa de vegetação, sem ferimento. Para manter a umidade após a inoculação, as plantas foram cobertas com sacos plásticos e mantidas em bandejas com água dentro de uma câmara de incubação a $25{ }^{\circ} \mathrm{C}$, durante $72 \mathrm{~h}$. Vinte mudas sadias, pulverizadas com água destilada e esterilizada, serviram como testemunhas. Tanto as plantas inoculadas, quanto às sadias foram transferidas para uma casa de vegetação com temperatura e umidade relativa variando respectivamente, entre $20-30{ }^{\circ} \mathrm{C}$ e $40-50 \%$.

Sete espécies de gramíneas, incluindo duas cultivares de $P$. maximum, foram inoculadas com o isolado de $B$. maydis em estudo, utilizando-se o mesmo método de inoculação.

Para avaliar a associação de $B$. maydis com sementes de Pojuca, 400 sementes de um lote colhido em 2002, no mesmo campo onde foi verificada a presença de lesões foliares, foram esterilizadas superficialmente com $\mathrm{NaOCl}$ a $1 \%$, durante $5 \mathrm{~min}$. Em seguida, foram lavadas com água estéril e incubadas em placas de Petri com BDA a $25 \pm 1{ }^{\circ} \mathrm{C}$, durante quatro dias em regime constante de luz branca

$\mathrm{O}$ isolado de Bipolaris sp. em estudo foi identificado pelo Dr. P.M. Kirk como Bipolaris maydis (Nisik. \& Miyake) Shoemaker [sinônimos: Helminthosporium maydis Nisikado \& Myiake e Drechslera maydis (Nisikado) Subramanian \& P.C. Jain)], forma teliomórfica Cochliobolus heterostrophus (Dreschsler.) Drechsler. (IMI 389321). As colônias do fungo mostraram-se escuras após quatro a cinco dias de incubação a $25 \pm 1{ }^{\circ} \mathrm{C}$ sob luz branca constante. Os conídios crescidos em BDA apresentaram-se marrom-escuros, predominantemente curvos, multiseptados, afilados nas extremidades e sem hilo saliente, isto é, tinham as carcaterísticas genéricas descritas para o gênero Bipolaris (Alcorn, 1983; Sivanesan, 1987). Quando crescidos em folhas de Pojuca, os conídios tinham 4-12 pseudoseptos, cor e características morfológicas semelhantes aos crescidos em BDA, e as dimensões variaram de $10,0-17,5 \mu \mathrm{m}$ de largura na parte mediana por $60-145 \mu \mathrm{m}$ de comprimento.

Os primeiros sintomas de manchas foliares apareceram em todas as mudas inoculadas, quatro dias após a inoculação. As lesões novas eram pequenas e elípticas, tornando-se alongadas e necróticas que mais tarde coalesceram-se, apresentando coloração cinza a pardo com halo escuro (Figura 1-B). As mudas testemunhas permaneceram assintomáticas. O reisolamento de $B$. maydis completou os postulados de Koch, confirmando-se assim ser esse fungo o agente causal das manchas foliares de Pojuca.

Todas as espécies de gramíneas testadas apresentaram sintomas de manchas foliares após inoculação $\operatorname{com} B$. maydis (Tabela 1). O capim Pojuca foi usado como controle positivo, servindo para comparação com as demais espécies. Esse capim é, portanto, uma nova hospedeira natural do fungo B. maydis.

Considerando-se a extensão das lesões necróticas nas folhas de Pojuca, causadas por B. maydis, os danos são consideráveis com redução de área fotossintética e perdas de produção de massa verde e, conseqüentemente, de sementes nos campos infetados por esse fungo. O isolado de B. maydis de milho (Zea mays L.) sobrevive na forma de micélio e conídios em restos culturais de milho (Carson, 1999), de onde é disseminado para plantas de milho e/ou de outras gramíneas suscetíveis. Para o isolado de B. maydis em estudo, não se conhece a sobrevivência em restos culturais de Pojuca, mas considerando-se que essa gramínea é perene, um campo infetado pode servir de fonte de inóculo durante longo período de tempo. Além disso, outras gramíneas forrageiras perenes são suscetíveis a esse fungo (Tabela 1), podendo, portanto, servirem também de fonte de inóculo de $B$. maydis.

De 400 sementes analisadas, 5\% estavam infetadas por B. maydis. Para avaliar a patogenicidade desse isolado, foi preparada uma cultura monospórica de uma das colônias e efetuado o teste de patogenicidade em $P$. atratum e sete outras espécies de gramíneas, seguindo a metodologia descrita

TABELA 1 - Reação de espécies de gramíneas à infecção quando inoculadas com Bipolaris maydis isolado de folhas e de sementes de Paspalum atratum cv Pojuca

\begin{tabular}{lcc}
\hline & \multicolumn{2}{c}{ Plantas infetadas } \\
\cline { 2 - 3 } Espécie & $\begin{array}{c}\text { Isolado } \\
\text { das } \\
\text { folhas }\end{array}$ & $\begin{array}{c}\text { Isolado } \\
\text { das } \\
\text { sementes }\end{array}$ \\
\hline Milho (Zea mays L.) cv. BR 106 & + & + \\
Arroz (Oryza sativa L.) Primavera & + & + \\
Cevada (Hordeum vulgare L.) AF 9585 & + & + \\
Capim Vencedor (Panicum maximum Jacq.) cv. Vencedor & + & + \\
Milheto [Pennisetum glaucum (L.) R.Br.] cv.BN 2 & + & + \\
Capim Brachiaria (Brachiaria decumbens Stapf) cv. Brasilisk & + & + \\
Trigo (Triticum aestivum L.) cv. Embrapa 22 & + & + \\
Capim Tanzânia (P. Maximum Jacq.) cv. Tanzânia & + & + \\
Capim Pojuca (Paspalum atratum Swallen) cv. Pojuca & + & + \\
\hline
\end{tabular}


na avaliação do isolado da parte aérea. Das 20 plantas de Pojuca inoculadas, 16 (80\%) expressaram sintomas de mancha foliar, quatro dias após a inoculação. As demais gramíneas avaliadas, à semelhança da reação ao isolado de B. maydis da parte aérea, mostraram-se suscetíveis também ao isolado das sementes de Pojuca (Tabela 1).

Este é o primeiro relato da ocorrência natural de mancha foliar causada por B. maydis em P. atratum cv. Pojuca, no Brasil.

\section{REFERÊNCIAS BIBLIOGRÁFICAS}

ALCORN, J.L. Generic concepts in Drechselera, Bipolaris and Exserohilum. Mycotaxon XVII:1-86. 1983.

CARSON, M.L. Southern corn leaf blight. Compendium of Corn
Diseases. AmericanPhytopathological Society, $3^{\mathrm{a}}$ ed., St. Paul, 1999.

EMBRAPA CERRADOS. Capim Pojuca (Paspalum atratum), capim nativo alta produção e qualidade. Folder, Embrapa Cerrados, Brasília, DF, 2000.

LEITE, G.G. \& FERNANDES, F.D. Qualidade da forragem do capim Paspalum atratum cv. Pojuca. Comunicado Técnico ${ }^{\circ} 9$, Embrapa Cerrados, Brasília, DF, 1999.

LEITE, G.G., FERNANDES, F.D. \& GOMES, A.C. Crescimento e composição química de capim Paspalum atratum cv. Pojuca. Boletim de Pesquisa e Desenvolvimento ${ }^{\circ} 19$, Embrapa Cerrados, Brasília, DF, 2001.

SIVANESAN, A. Graminicolous species of Bipolaris, Curvularia, Drechslera, Exserohilum and their teleomorph. Mycological Papers 158:1-259. 1987. 